\title{
La representación como imaginario social
}

The representation as a social imaginary

\section{Pedro Felipe Díaz Arenas ${ }^{1}$ \\ Yhon Jairo Acosta Barajas ${ }^{2}$}

\author{
Díaz A, Pedro F. Acosta B, Yhon J \\ miradas $\mathrm{N}^{\circ} 1$ - 2018 ISSN digital $\mathrm{N}^{\circ} 2539-3812$ Págs 204 - 217 \\ Recepción: Agosto 12 de 2017 \\ Aprobación: Mayo 25 de 2018 \\ Publicación: Junio 29 de 2018
}

\section{Resumen}

El presente articulo dará una mirada previa a la realidad social con relación al imaginario, busca identificar los imaginarios como experiencia urbana, un modo de ser ciudadano, en este sentido la ciudad es el lugar donde converge y se producen nuevas formas de percibir y de vivir. Los estudios en esta investigación son las nociones y conceptos enmarcados en las teorías y metodologías del doctor Armando Silva y el proyecto internacional de ciudades imaginadas.

Palabras clave: Imaginario, representación, estética, territorio.

\section{Summary}

In the present article will give a preliminary look at the social reality in relation to the imaginary seeks to identify the imaginaries as urban experience, a way of being a citizen, in this sense the city is the place where it converges and new ways of perceiving and living are produced. The studies in this research are the notions and concepts framed in the theories and methodologies of Dr. Armando Silva and the international project of imagined cities.

Keywords: Imaginary, representation, aesthetics, territory.

1 Doctor en Ciencias de la Educación, Área Pensamiento Educativo y Comunicación. Magíster en Comunicación Educativa de la Universidad Tecnológica de Pereira. Docente investigador adscrito a Comunicación Social - Periodismo. pedrofelipediaz@gmail.com Universidad del Quindío, Colombia.

2 Doctor en Ciencias de la Educación. Magíster en Comunicación Educativa. Licenciado en Etnoeducación y Desarrollo Comunitario. Universidad Tecnológica de Pereira. Docente catedrático Facultad de Ciencias Basicas. Grupo de investigación en Comunicación Educativa. yjacosta@utp.edu.co. Pereira, Risaralda,Colombia. 


\section{La pregnancia como construcción social de la realidad}

Es importante mencionar que el concepto de pregnancia simbólica ${ }^{3}$, al que alude Silva en el marco de la estructura del Imaginario Urbano, nos lleva a comprender la imaginación simbólica en un sentido connotativo. Lo que quiere decir que el significado construido simbólicamente no se asocia con una cosa específica en cuanto

\section{Introducción}

El documento indaga sobre las formas propias de la cultura urbana contemporánea, entendida esta como el espacio de realización de la comunicación y la dimensión simbólico - expresiva de las prácticas sociales de los ciudadanos, interpretadas como unidad estética desde los imaginarios urbanos. En otros términos, es generar procesos de comprensión de lo urbano desde las dinámicas y relaciones con la realidad social. A través de algunos fenómenos urbanos que tienen lugar dentro de la contemporaneidad de la urbe. Estos serán los puntos de partida para interpretar categorías y conceptos de la teoría de los imaginarios.

En efecto, se busca identificar los nuevos urbanismos creados por los ciudadanos desde la interacción cotidiana y profunda, en su relación con la ciudad. En la reflexión sobre imaginarios urbanos, se busca conocer la subjetiva y comprender los múltiples contextos que hacen configurar y significar a la urbe desde los relatos de sus habitantes, la memoria histórica colectiva sobre sus espacios o lugares; los cuales son calificados por los habitantes de acuerdo con unas cualidades simbólicas surgidas a partir de la experiencia cotidiana del ciudadano con su urbe. tal, a una palabra definida o una expresión única, sino que evoca un sentido o muchos que pueden abarcar la expresión simbólica en su condición polisémica.

Silva retoma de Ernst Cassirer el concepto de pregnancia simbólica, con el que este último "refiere la impotencia que condena al pensamiento a no poder intuir algo sin dejar de relacionarlo con uno o muchos sentidos". (Silva, 2006, p. 92). Según Silva, tal concepto de pregnancia simbólica lleva a pensar que en la conciencia humana nada se reproduce de manera literal: siempre hay una interpretación. En la conciencia humana nada es presentado, sino representado. La conexión que establece Silva entre pregnancia simbólica e imaginario lleva a entender este último como una invención. Tales estructuras psíquicas inconscientes son abordadas desde la reflexión psicoanalítica, la cual, según Christian Metz, citado por Silva, se constituye en un esfuerzo por desprender el objeto de la estructura psíquica de lo imaginario y ganarlo para lo simbólico. Se establece entonces una relación entre lo simbólico y lo imaginario; lo primero entendido como la palabra, la elaboración secundaria y lo segundo como las huellas, como lo anterior a la palabra.

3 Concepto que Silva introduce y desarrolla en su teoría a partir de la visión de Ernst Cassirer, filósofo alemán de principios del siglo XX. Autor de obras como Idea y forma (1921) y Filosofía de las formas simbólicas (1923-19). 
Sin embargo, según Silva (2003) ese carácter de representación colectiva no otorga a los imaginarios "la condición de un arquetipo fundamental, sino la condición de una forma transitoria de expresión, de un mecanismo indirecto de producción social, de una sustancia cultural histórica". (p. 22)

Así, la propuesta teórica de Silva establece, como derivación del esquema tríadico, tres grandes categorías de análisis que han servido como derrotero para el proceso de comprensión y sistematización de la producción y reproducción de los Imaginarios Urbanos. La presentación y explicación de estos ejes se hace necesaria para el entendimiento en la relación imaginario urbano y estética de lo accidental, ya que en las teorías modernas es necesario entender como se configuran realidades, para el caso es desde donde se genera gran parte de los imaginarios; retornando a Peirce, primeridad y segundidad; luego la terceridad. Recordemos que la fenomenología de este último autor se fundamenta en la triada para crear nuevas teorías y de allí se desprende su método de abducción, pero aquí se define el imaginario como el proceso psíquico perceptivo en tanto que se entiende motivado por el deseo y cuando lo que se atiende no es su representación ni su descarga satisfactoria, sino a una forma de aprehender el mundo. Si lo que nos interesa es la representación, se está en el dominio de la lógica; si lo que se enfoca es el cuerpo como tensión del goce y descarga del placer, estamos en el dominio del psicoanálisis. Pero si la búsqueda pretende comprender los modos de aprendizaje del mundo desde una posición de sujetos, hablamos de imaginarios. Desde esta posición del ser social, los imaginarios han de agregar otra premisa que ya se señaló: son colectivos -y por ello públicos- y se estudian desde sus modos sociales de conocer. En consecuencia, los imaginarios urbanos abarcan las culturas ciudadanas desde donde se avanza hacia la construcción de una perspectiva del sentir ciudadano como expresión de deseos hechos colectivos por su coincidencia en la búsqueda del mismo objeto. Como podemos ver en la siguiente grafica al indagar la categoría de ciudad podemos analizar la proporcion de aceptacion de dicho concepto tomando de referencia cinco ciudades imagiandas: Esta categoría sobresale como referencia de ciudad a Bogotá, con 201 equivalente a un $0.95 \%$ seguida de Pereira con 174 que equivale a un $0.89 \%$ y Sao Pablo 156 equivalentes a un $1.53 \%$. En la ciudad se agrupan las referencias en su sentido físico histórico. Por tal motivo es supremamente relevante entender la ciudad construida por sus habitantes. Se argumenta que la ciudad es arte en su sentido espacial, por ser la arquitectura un arte visual, la relación entre ciudad arte y lo urbano es un acontecimiento más allá de lo cotidiano.

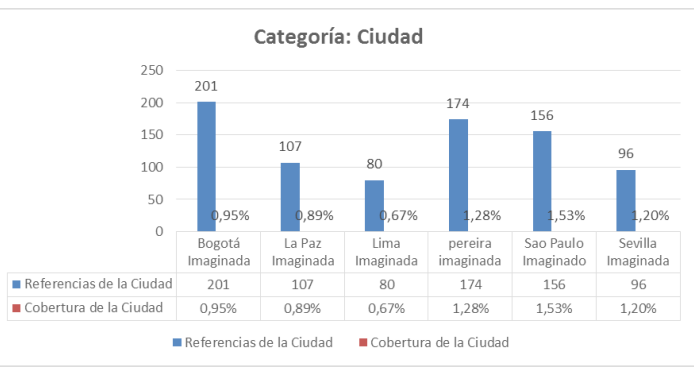

Tabla elaborada por Pedro Felipe Díaz y Yhon Acosta Barajas

Esto nos lleva a pensar la ciudad y lo ciudadano a partir de esos vínculos esenciales, que representan la génesis de lo urbano, que se van tejiendo esas formas 
imaginadas de comprender y construir la realidad social de la ciudad. Paralelo a ello los accidentes estéticos van surgiendo de modos siempre disimiles. Del tal manera que la forma en la que se percibe, interpreta y significa la ciudad desde lo imaginado, corresponde a esas cualidades urbanas, sus clasificaciones y escenarios que se relacionan a su vez con las temporalidades, las marcas ciudadanas y las rutinas. Todo ello genera una identidad mediada por lo imaginado, que muta constantemente hacia otras posibilidades de encuentro y reconocimiento. Lo estético, en este sentido, viene dado por los fenómenos que se derivan de esa amalgama de relaciones que construyen las personas desde lo real y lo imaginado.

Ahora bien, el accidente, como ya se expuso al iniciar este escrito, en sus modos accidentales de las situaciones y sus formas accidentales respecto de las naturalezas materiales, surge y desaparece en un proceso constante de cambio, a diferencia de la sustancia que solo modifica su estado a raíz del cambio de dichos accidentes. De ahí que, si comprendemos, para ejemplificar tan solo un caso, la ciudad desde sus cualidades urbanas, estaríamos aludiendo al imaginario que se crea en torno a un aspecto, digamos color, de la ciudad ${ }^{4}$. Lo que nos dará unas calificaciones respecto de ese aspecto. Lo notable es que estos estados imaginados afectan y dinamizan algunas de las rutinas ciudadanas ya sea temporal o permanentemente. Además de las percepciones que generan las otredades con base en este tipo de cualidad. Una ciudad puede ser verde o pasar de ser

4 En el marco del proyecto de Imaginarios Urbanos, al preguntarle a los habitantes de diferentes ciudades en Latinoamérica con qué color identificaban su ciudad, algunos de los resultados fueron: Quito: azul, Medellín: verde, Bogotá: gris, Caracas: verde, La Paz: gris plomo. negra a ser blanca (segura o peligrosa/ alegre o triste desde lo connotativo), puede pasar de ser percibida como una ciudad de caos a ser tranquila. Lo que genera un cambio en la forma de representación y consecuentemente en el estado imaginado de esa ciudad. Este aspecto cromático de cualidad, que se inscribe a un fuero estético, puede aplicarse a menor escala con una calle, parque o plaza. Igualmente los olores, sonidos, personajes o acontecimientos que encarnan una cualidad o determinación en torno a un lugar, adquieren esas marcas accidentales que generan particularidades estéticas y dinamizan la actividad social. Recorridos, territorialidades, usos, desplazamientos, entre otros. En la siguiente grafica podemos identificar el uso del concepto lo simbólico atribuido a lo construido por las culturas. Lima con 13 referencias y una cobertura de $0.16 \%$ es el de mayor representatividad. Sao Paulo con 8 referencias y con cobertura de $0.12 \%$. Sevilla con 5 referencias y un $0.09 \%$. Bogotá con 2 referencias y con una cobertura de $0.1 \%$ y Sao Paulo con 1 referencia y una cobertura de $0.01 \%$

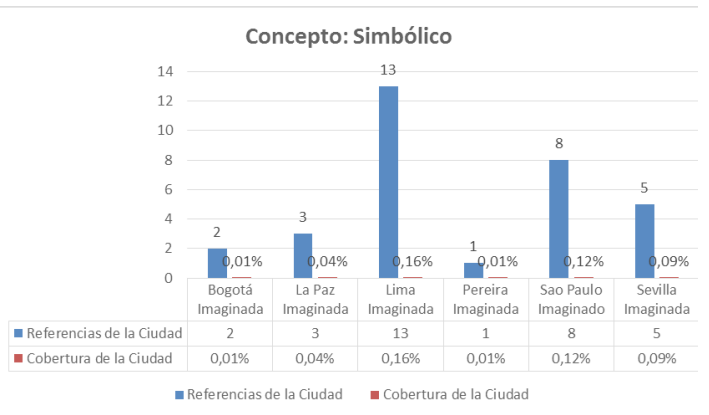

Tabla elaborada por Pedro Felipe Díaz y Yhon Acosta Barajas

La protesta, los desfiles o las festividades en espacios públicos ${ }^{5}$, en donde esa interacción 5 Para Silva estos fenómenos se presentan como nichos estéticos, en donde se genera una serie de juegos estéticos, que irrumpen en el espacio urbano con alguna originalidad 
entre las personas y su entorno puede llegar a resignificar esos espacios y por ende sus funciones y usos, corresponde a otra de esas formas de manifestación de la estética de lo accidental. Pues derivado de ese conjunto de relaciones, formas y sentidos el escenario urbano consigue modificarse momentáneamente, ósea, pasar de un estado a otro. Una calle que es concebida para la movilización de vehículos puede convertirse en un momento dado en una pista de baile o en un escenario de discusión política. Como lo expone el proyecto de Imaginarios Urbanos, el accionar del habitante es fundamental en la construcción colectiva de las representaciones, pues es este el que exterioriza los deseos, anhelos, miedos y demás sensaciones que se conciben desde ese ser urbano. Así, Lindón (2006) nos menciona que:

Hay una labor de un
imaginario del habitar en el
que se fantasea y se construye
algún tipo de referencia de
realidad a partir de lo no
estructurado. (...) En torno a
este ocurren apropiaciones
invisibles que, como tales,
no se inscriben directamente
en el espacio, sino en las
aspiraciones y fantasías de los
habitantes. (p. 144)

Para la comprensión de una estética de lo accidental es menester, desde la concepción de Silva (2013) "comprender la construcción de los croquis ciudadanos, en el sentido de reconocer las formas que habitan en las mentes de estos por de formas o con cierto impulso creativo, de producir un efecto en lo social y que a partir de esa experiencia, se construya alguna cohabitación grupal que permita a sus asociados ampararse, representarse o imaginarse como colectivo. Lo que aquí proponemos es que esos juegos estéticos a los que alude Silva, son de naturaleza accidental. segmentación e interiorización de sus espacios vividos y su proyección grupal según distintos puntos de vista urbanos". (p. 173) (Ver foto 3 y 4)

De tal forma, podemos concluir, de acuerdo con el enfoque de Mukařovský el imaginario desde su manifestación estética no está en el objeto, sino que se incorpora a él para su percepción social dotándolo de otros significados que están sujetos a cambio de percepciones de acuerdo con ese hecho de re-habitación sensorial. (Silva, 2013) El abordaje, desde la estética de lo accidental, es tema a agotar en el marco de los Imaginarios Urbanos. Dado que las dimensiones estéticas del mismo son el resultado de esas otras maneras de construcción y reconocimiento del sujeto -colectivamente- en un mundo copado de tenciones entre el comercio, las tradiciones, la política, el arte, la cultura y los entornos virtuales.

\section{EI Imaginario y lo urbano}

Lo percibido a finales del siglo XIX y durante el siglo $\mathrm{XX}$, en la atmósfera e influjo del pensamiento, se puede sintetizar bajo el interés que despertó el concepto del lenguaje. De aquí nacen y se ramifican en escuelas, corrientes y grandes figuras del horizonte reflexivo que indagaron, teorizaron y postularon, en el campo lingüístico, posiciones y tesis que influirían en diferentes ámbitos del conocimiento. Reflexiones filosóficas, desde la física y la biología, hasta influjos del pragmatismo y el existencialismo, entre muchos otros, constatan lo anterior. Las ciencias naturales y las ciencias que Dilthey denominó ciencias del espiritu, se verían, en este sentido, escudriñadas por los estudios que desde el lenguaje se generaban, algunos ejemplos facilitaran enmarcar esta idea. 
En Norteamérica, la filosofía del lenguaje con Austín, Searle y Moore, perfiló sus investigaciones desde el análisis del lenguaje. En el mismo lugar el pragmatismo, acentuado en la obra de Perce y los planteamientos tanto Rorty como de Dewey que también se introdujeron en el terreno de la lingüística. Desde Europa, el estructuralismo con Saussure, Levi Strauss y Barthes a la cabeza, sondearían y reflexionarían sobre los intereses del habla, del texto y la palabra.

El deconstruccionismo propulsado por Derrida traería la impronta lingüística, no en vano su monumental obra de prólogo escritural optaría por llamarse Gramatología. A manera de cierre de esta apretada síntesis, también podemos considerar el desarrollo que hasta el presente traen consigo los estudios sobre semiótica, esbozada por la conjunción anglo - itálica de los estudios de Chomsky y Umberto Eco.

Hoy por hoy, se entiende que el lenguaje no sólo se limita a la expresión escrita o hablada, un modelo uniforme que, a fin de cuentas, era la idea central que el primer Wittgenstein presentó a través de su Tractatus lógico-philosophicos, obra que serviría a la postre de argumento apologético del positivismo lógico, corriente que ubicaba el lenguaje representando casi físicamente la realidad. De esta forma, trataban de manipular directamente esta misma realidad. El propio Wittgenstein modificaría radicalmente su postura al escribir una nueva obra que tituló Investigaciones Filosóficas. Por ello, afirmamos que de un mismo pensador nos vienen dos ideas antagónicas con respecto a sus tesis lingüísticas, estableciéndose una consideración especial al definir al primer $y$ al segundo Wittgenstein dentro de las discusiones y referencias que se asumen de este autor. El segundo Wittgenstein, adquiere conciencia clara de la riqueza y diversidad de las formas lingüísticas. El cambio presente en Wittgenstein divisa la dinámica del lenguaje a lo largo del siglo XX, de manera especial, Austin plantea:

Unalengua consiste en realizar
actos de habla, actos tales
como hacer afirmaciones, dar
órdenes, plantear preguntas,
hacer promesas, etc., y más
abstractamente, actos tales
como referir y predicar; y,
en segundo lugar, que estos
actos son en general posibles
gracias a, y se realizan de
acuerdo con, ciertas reglas
para el uso de los elementos
lingüísticos (Austin, 2008, p.
73 ).

Ferdinand de Saussure se erige como oficiante del primer momento, su apuesta por constituir un sistema que permitiese abordar la estructura de la lengua devino en la obra más reconocida en los estudios de la lingüística moderna, Cours de Linguistique Génerale (1916) donde se aborda el estudio del signo a partir del binomio significado (unidades de contenido) y significante (unidades formales). De igual manera, la mirada dicotómica se hace presente en sus estudios con la dupla categorial de lengua y habla, la primera entendida como el sistema estructural general que subyace en cualquier lenguaje, la segunda, el habla, como la que se presenta en las particularidades y usos propios de diferentes contextos que operaria más en sentido connotativo.

La apuesta de Saussure se encamina hacia la formalización de un sistema que desde la impronta positivista permita la consolidación y legitimación de la 
lengua como objeto de estudio con las condiciones que demarca el estatuto de la ciencia moderna. Esta postura encuentra elementos colindantes con los postulados que en su clásica obra, Introducción al Estudio de la Comunicación (1982), Fiske analiza como correspondiente a la escuela centrada en el proceso. Para este último autor, son dos los modos que desde el plano teórico se manifiestan al encarar el estudio de la comunicación, por una parte, el enfoque que asume la comunicación como transmisión de mensajes, categorías tales como codificación, decodificación, transmisor y receptor, entre otras, se presentan como constitutivas de su horizonte discursivo encaminadas a analizar actos de comunicación, la dimensión abordada por esta mirada se limitará a situar su estudio a todo lo que se refiere al nivel técnico.

Por otra parte, Fiske señala el enfoque que considerala comunicación comoproducción e intercambio de sentido, donde se analiza la manera en cómo los textos interactúan con el entorno y los sujetos para producir sentido. El horizonte discursivo de este enfoque acude a las artes y a la lingüística para abordar ya no actos, sino obras de comunicación. El modelo de comunicación que desde el ámbito de la matemática y la ingeniería presentarán Shanon y Weaver es por antonomasia la concreción de lo que se entiende por proceso: una secuencia, con pasos a seguir, linealmente, sin oportunidad de retroalimentación, donde lo que se pretende ubicar son las interferencias que perturban e interrumpen la transmisión de una información que se emite de un punto $A$ a un destino $B$, donde la dinámica de la comunicación se centraría de manera especial en el dispositivo más que en el actor de la misma, allí se advierte claramente la disyunción moderna entre objeto y sujeto, donde el dispositivo como objeto de la misma se roba la atención del acto comunicativo, una clara disensión respecto de la visión de Fiske.

\section{El imaginario y su resignificación}

Acogiendo la ruta planteada por Silva (1997), se dirá que los estudios del lenguaje encausarían su atención luego de un primer momento lingüístico hacia las distintas prácticas sociales que, en concordancia operacional con la lengua, serían susceptibles de ser estudiadas desde tesis semiológicas y hermenéuticas. Si ya hablamos de una primera escuela centrada en el proceso, tendremos que mencionar que a la postre emergería gracias a la dinámica propia del lenguaje y el entendimiento por parte de algunos autores descentralizados, una segunda escuela, denominada semiótica, la cual consideraría la comunicación como producción e intercambio de significados, en el que se da una interacción entre textos y personas para generar sentidos al momento de abordar obras de comunicación. Estos dos enfoques presentes en las escuelas del proceso y la semiótica, plantean la dicotomía comunicación - información y comunicación - significación, el tránsito entre una y otra permite advertir, por ejemplo, que el lenguaje deja de centrar su atención en los dispositivos para indagar en torno a los sujetos participes del acto comunicativo, de tal forma que la semántica de emisor - receptor objetual toma un viraje hacia la de autor - lector vivencial, ya no simplemente entregando y recibiendo una información a través de un mensaje, sino en un punto de encuentro nodal denominado como texto. 
Lo anterior puede verse precisado a través del escenario donde se desarrollan las prácticas sociales, en palabras de Finol (2006): "el espacio es una estructura semiótica que cumple un papel fundamental en la organización de la cultura (...) se convierte en instrumento simbólico, capaz de articular los contenidos de la cultura misma en una sintaxis particular" (p. 95), para la escuela semiótica los lugares y objetos de la vida diaria son, por su propia naturaleza, ordinarios y sus significados sociales no son siempre evidentes, aquello que se considera como sentido o vida común - experiencia que se expone en el teatro de la vida - guarda tras bambalinas motores que impulsan formas de relación con el otro, consigo mismo y con su entorno. La configuración del territorio como escenario en el que se concretizan prácticas, devela una serie de huellas, que en determinados lugares pueden llegar a establecerse como fuertes vínculos en torno a las relaciones que dicho ambiente despierta en quienes lo vivencian, relación que por demás sobrepasa las fronteras espaciales.

En esta línea de pensamiento se precisa e indica que la lectura no puede seguir siendo reducida a un ejercicio tipográfico que conjuga morfemas para articular palabras que construyen oraciones y estructuran parráfos que se insertan en capítulos literarios, la lectura a la que se alude conlleva a levantar la mirada para apreciar la multiplicidad de textos ( Vásquez, 2004) que ofrece la vida misma, realizar el tránsito barthesiano de la obra al texto, del corpus tangible expuesto por el autor al sentido intangible que subyace y recae sobre el lector.
La ciudad, en tanto texto, es un ejemplo claro de la lectura que se referencia, toda vez que como cual palimsesto que además de ofrecer la posibilidad de ser leida, despierta el ánimo para ser escrita, expresada y relatada a través del sentir de quienes la viven y la recorren, de allí el modo concreto del operar analógico que estableció el movimiento del estudio del lenguaje alrededor de la lengua y las prácticas sociales.

Como hemos visto la incorporación de la semiótica a los estudios comunicacionales permitiría, a partir de la década de los setenta, una integración a las dinámicas sociales y nuevos modos de abordar diferentes esferas de la vida social. La hegemonía del libro y del lenguaje escrito que imperaba en un primer momento para el estatuto comunicacional, se verá movilizada en esta etapa donde ocurre un descentramiento del lenguaje, lo que conllevará a nuevas asunciones y formas de lectura, como la de la imagen.

\section{La ciudad y lo estético}

La evocación que realiza Silva (1997) a Freud al plantear las formas afectadas por los sujetos pulsionales, es inminente, y es así toda vez que las formas subjetivas del sentir se manifiestan por este autor en una obra que resquebraja la razón unitaria y la unidimensionalidad lingüística que caracterizaba el pensamiento de inicios del siglo XX, hablamos de la Interpretación de los Sueños (190, 344-720), dicha obra, escrita apenas algo más de una década anterior al Cours de Linguistique Génerale de Sausurre, conllevó asumir formas de expresión que transitan por el inconsciente, desbordando el marco del lenguaje tradicional. La comunicación del deseo 
en los sujetos implica la consideración de un saber del inconsciente que despliega y sobrepasa la lingüística, acentuando el fenómeno estético contemporáneo, que Kierkegaard llamará en $O$ lo uno o lo Otro (2006), como existencia estética. Lenguaje y estética, no se reducen a una cuestión filológica. El lenguaje es plurisémico, amplio y vasto:

\section{El lenguaje es un gran <campo semántico> intrincado y complejo. Esta relación implica que ese gran campo de significados está imbricado con el hombre, ya que el lenguaje no solo dice lo real sino que también expresa las vivencias y los distintos <estados del alma>. La interpretación es así un arte (tekne), del conocimiento (episteme) profundamente unido con el lenguaje y con el hombre. (Echeverry. 2005, p. 8)}

El filósofo alemán Karl Otto-Apel (1985) escribe que "la experiencia estética nos hace vivir otros mundos posibles" ( $\mathrm{p}$. 86). En la medida que la comunicación deja de ser considerada tan sólo como transmisión de información, y se asume como generadora de sentido, da la apertura a la transformación de la vida, posibilita otros escenarios y moviliza nuevos actores sociales, de tal forma que en el campo de estudio se presenta un abordaje de la comunicación como acontecimiento de reconocimiento del otro y de lo otro. La comunicación, en esta consideración, lleva a la designación de una existencia relacional - interpersonal - satisfactoria encaminada a una mejor convivencia entre el sujeto y su entorno. Bello parentesco dado entre comunicar, comunión y comunidad, filiación lingüística y psíquica que gesta el intercambio y la reciprocidad, pero que, valga decir, no se agota en la signatura. Ahora bien, la ciudad puede ser entendida a la par como un sistema estructurado de sentidos y formas que comunican. Allí el sujeto que la habita puede construir su universo significante en relación con los otros y su entorno. Por tal motivo, podemos mencionar que:

En términos muy generales
podemos decir que
imaginamos lo que no
conocemos, o lo que no
es. En otras palabras, lo
imaginario remite a un campo
de imágenes diferenciadas de
lo empíricamente observable.
Lo imaginario corresponde a
elaboraciones simbólicas de
lo que observamos o de lo que
nos atemoriza o desearíamos
que existiera. (García
Canclini, 2007, p. 90)

Se debe considerar entonces, que bajo el modelo legado por el proyecto semiológico y su interés por los códigos que hacen posible la comunicación, la interacción, el reconocimiento; la creación, configuración y reconfiguración de sentidos e identidad, se puede leer la ciudad como si fuera un texto. Para Barthes (1990) "la ciudad es un discurso, y este discurso es verdaderamente un lenguaje: la ciudad habla a sus habitantes" (p. 260). Pero también, valga añadir, habla de ellos y de sus costumbres, hábitos, rutinas, miedos, problemas, entre otros tantos aspectos que pueden ser entendidos como huellas o índices que se generan de una época a otra o son particularidades de 
un tiempo y un espacio determinados.

[...] llegamos a establecer que la función de la imaginación es ante todo una función de eufemización, aunque no mero opio negativo, máscara con que la conciencia oculta el rostro horrendo de la muerte, sino, por el contrario, dinamismo prospectivo que, a través de todas las estructuras del proyecto imaginario, procura mejorar la situación del hombre en el mundo. (Durand, 2000, p. 126 -127)

Lo anterior podría considerarse como efecto de la acción social de los sujetos en torno a su urbe. Una especie de caligrafía axiológica que va tejiendo el complejo entramado de relaciones entre los ciudadanos y su ciudad. De allí la derivación de una idea que se ha venido mencionando discretamente tanto en este capítulo como en otros: lo estético como resultado de la actividad cotidiana y recíproca del sujeto con su entorno.

Debemos subrayar, con base en lo antes indicado, que la creación de elementos técnicos y tecnológicos que median en los procesos comunicativos y que afectan directa o indirectamente la relación signica, psíquica y afectiva del sujeto con su entorno, también juega un papel importante en toda la configuración de lo estético, pues como actores sociales, actuamos e interactuamos, como ya se ha mencionado, intercambiando experiencias por medio de signos, códigos y artefactos que cargamos de sentido. El hombre, en tanto actor, se implica también como "factor en dos campos: el campo del arte facción y el campo de la significancia o significación” (Ávila, 1994, p. 132); el primero, indica que el hombre es artífice del arte factum, artificialmente crea artefactos, producción instrumental, campo específico de la tecnología. El segundo, señala la producción de signos y de significación. El hombre como tejedor de urdimbres de significación en la trama de la vida.

Silva nos presenta la síntesis de lo planteado al señalar que:

De una $\mathrm{u}$ otra forma el estudio del lenguaje: qué es, qué se sabe, qué hacemos creer con las palabras o qué hacemos para que se hagan acción, preguntas que nutrieron el proyecto lingüístico moderno en este siglo, termina con la consolidación de un paradigma más bien estético: cómo sentimos, cómo vamos, cómo conciliamos el saber con el sentir. Pareciese entonces tener lugar una evolución de los "qué" (de las estructuras) hacia los "cómo" (de las pasiones y los sujetos). (1997, p. 205)

De tal manera, el lenguaje transita en la apertura del siglo XXI a nuevas configuraciones en las cuales, de manera singular, la dupla tecno - estética adquiere grandes connotaciones, pues su movilidad en la denominada Era de la Información - Castell- nos invita a considerar el papel de las TIC $^{6}$ en las dinámicas sociales y el impacto en el ámbito comunicativo, sin que se trate de evocar y regresar a la rezagada mirada técnicista. De tal manera, que los diversos recorridos por el imaginario

6 Tecnologías de la Información y de la Comunicación. 
ciudadano, se materializan con la imagen y el significado de las palabras, que implican a su vez un transitar por lo mediático urbano, de donde se deriva un nuevo trazado de habitad en las urbes. Con ello se acuña la re-significación permanente de los acontecimientos y de los modos de habitar lo cotidiano, en este sentido Silva (2006) nos menciona que "en el interior de las ciudades coexisten distintos territorios, abrumados hoy por el entrecruce planetario de la comunicación de los mass media" (p. 79). Este acontecimiento moviliza un cambio en el escenario dialógico desde la interacción, en el encuentro con el otro - en términos de Silva otredad - y con la necesidad de tejer otras territorialidades vitales para el encuentro entre los ciudadanos. Bienvenido pues el espacio virtual.

Consecuentemente Silva (2005) señala que:

Las polémicas en aumento que se vienen dando tanto en Colombia como en otros países sobre el uso del espacio virtual como expresión ciudadana (...), pasan por el descubrimiento de las posibilidades de este nuevo medio de redes abiertas e interactivas (distinto a la televisión, por ejemplo de carácter jerárquico y cerrado). En estos nuevos movimientos sociales de conexión virtual crece una poderosa cuidad imaginada que transporta anhelos de cambio, en la que se ajusta lo que puede ser el futuro en términos de realidad actual y lo que podría ser pensado con el deseo. Así se da el encuentro asombroso de un medio y -pienso que beligerante- de la multitud conectada con la ciudad imaginada. (p. 160)

De tal manera que la acción metafórica, el hacer simbólico, la transfiguración y reconfiguración de la realidad se da también desde la actividad misma del ciudadano en este otro espacio, ya que la imagen y la palabra aparecen como acción. Entonces, podríamos atrevernos a señalar que las acciones performativas y estéticas que emergen en la urbes y se muestran virtual y mediaticamente, son producto de la reflexión que realiza el ciudadano para comprender un medio estructurado por condiciones textualisadas que permean la esfera de la percepción y la acción.

En el concepto de cultura se destaca en la posición más alta Bogotá con 22 referencias de la ciudad y con $0.12 \%$ de la cobertura de la ciudad. En lo cultural hay para destacar como lo público se forma a la par con un sentido de lo urbano, con el uso de la ciudad o bajo prácticas culturales que son también la base para la construcción posterior del significado imaginario.

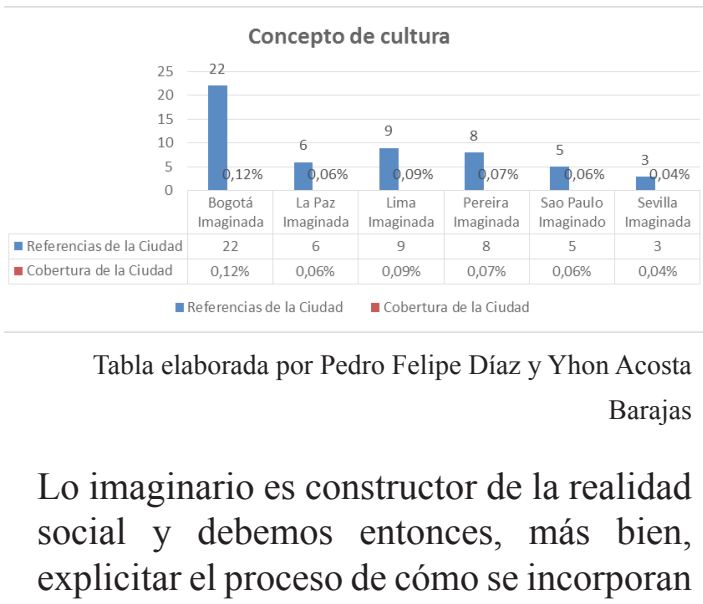


los imaginarios sociales en los entornos físicos de la ciudad y así proyectarlos como expresión de culturas ciudadanas. La ciudad de La Paz en el concepto de lo imaginado en el tema de la referencias de la ciudad, cuenta con 41 en representación de la ciudad y con un porcentaje del $0.63 \%$ en cobertura, en segunda instancia se encuentras Pereira con 33 en referencia y $0.44 \%$ en cobertura de la ciudad seguido de Lima con 32 en referencia y 0.49 de cobertura

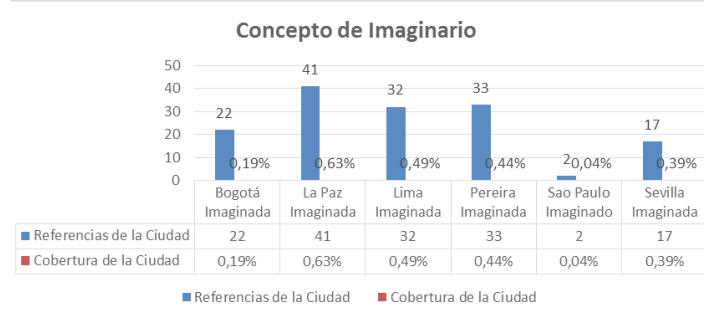

Tabla elaborada por Pedro Felipe Díaz y Yhon Acosta

Barajas

La aparición de lo imaginario, es producto de aquellas manifestaciones sensoriales y afectivas que los individuos configuran sobre su realidad material y virtual, ello para provocar en ellas aproximaciones, para denunciar lo que no se admite, para transgredir y subvertir esas normatividades que limitan el entorno urbano. En esta medida es el ciudadano quien crea su territorialidad y su ciudad, promoviendo escenarios de reflexión y confrontación por medio de expresiones estéticamente cristalizadas en imágenes textualizadas y mediatizadas que hacen de la ciudad un reflejo de múltiples interpretaciones y concepciones.

Las manifestaciones mediático/virtuales que generan imagen y atraviesan caminos imaginarios, tienen presencia en espacios cotidianos, de allí que; aunque son determinados y organizados, en alguna $u$ otra medida, por estructuras económicas, educativas y de política pública o del sector privado, no dejan de ser escenarios perfectos, en el marco de la subversión, para romper los dispositivos de poder y de control. A través de lo mediático se hacen presentes todas las posibles lecturas de los símbolos que, de una u otra forma, son los que hacen evidente las percepciones y visiones de lo urbano desdo los ciudadanos; dichos símbolos configuran el mundo imaginario para comunicar, evidenciar y permear la percepción social en torno a determinados fenómenos; lo que en un primer momento Silva determinó estudios de la comunicación, o su análisis del fenómeno social del significado del grafiti e incognito autor, y en otro momento su proyecto de álbum de familia donde desarrolló y visionó la metodología de lo que serían las ciudades imaginas en América Latina y Europa. ${ }^{7}$ Entonces los procesos de comunicación requieren apuntar a la decodificación de los signos - aparentes en que se nos presentan los lenguajes para que mediante su desciframiento podamos entrar a la estructura profunda donde está el auténtico significado de los fenómenos

7 Armando Silva desde la Universidad Nacional de Colombia genera un libro con una tendencia estructuralista titulado La comunicación visual comprendiendo la teoría y método para la lectura de las artes y sistemas visuales, editado por Suramericana en el año 1978. El interés por estudiar la significación o giro lingüístico como la interpretación estética, además del autor incognito lo llevo a estudiar los estudios de graffiti en la publicación Una ciudad imaginada Graffiti/Expresión urbana, editado por la Universidad Nacional de Colombia en el año 1986, en la misma línea con el Instituto Caro y Cuervo desarrollo el concepto punto de vista ciudadano, como focalización visual y puesta en escena del fenómeno del graffiti esto en el año 1987. Más adelante en el año 1998 incorporo en los estudios sociales la fenomenología del análisis de la imagen en el libro Álbum de familia que abordo más de 170 álbumes de familia. La imagen de nosotros mismos un estudio rigoroso de lo corporal de la cotidianidad que delata y como se encarna en el tiempo a través de la fotografía. Estudio publicado en varios idiomas. 
urbanos (Silva, 1978). Lo que nos lleva a pensar en la forma en cómo se elaboran los contenidos para su interacción social y adaptación cultural, mediática y tecnológica; además de cómo se leen y entienden.

\section{Referencia}

Apel, Karl - Otto. (1985). La transformación de la filosofía. Madrid, España. Taurus.

Austin J. (2008). Cómo hacer cosas con palabras. Barcelona: Paídos.

Ávila, Rafael. (1994). La educación y el proyecto de la modernidad. Bogotá. Ediciones Anthropos.

Barbero Jesús Martín y SILVA, Armando compiladores -. (1997). Proyectar la comunicación. Colombia. Tercer Mundo Editores.

Barthes, Roland. (1990). La aventura semiológica. Barcelona. Paidós Comunicación.

Durand G. (2000). La imaginación simbólica. Buenos Aires: Amorrortu editores.

Echeverry, Jorge. (2005). Documento de Hermenéutica. Seminario de ermenéutica en las ciencias sociales, realizado el 2 y 3 de abril de 2005 . Maestría en Educación. Universidad Católica de Manizales.

Flinol, José. (2006). Rito, Espacio y Poder en la Vida Cotidiana, en deSignis (sic), En Designis No. 9, -, Mitos y Ritos en las Sociedades Contemporáneas. Abril de 2006. FINOL, José Enrique (coordinador) Barcelona, España. Editorial Gedisa.
García Canclini, Néstor. (2007) ¿Qué son los imaginarios urbanos y cómo actúan en la ciudad? Diálogo con Alicia Lindon. Revista Eure. Vol. XXXIII, No 99, Santiago de Chile.

Kierkegaard, Soren. (2006). Escritos. Volumen 2. Madrid: Editorial Trotta

Lindón, Alicia; HIERNAUX, Daniel; AGUILAR, Miguel. (2006). Lugares e Imaginarios en la Metrópolis. Anthropos Editorial. Rubi. Barcelona - España.

Silva, Armando. (2003). Bogotá imaginada. Convenio Andrés Bello, Universidad Nacional de Colombia. Editorial Taurus, Bogotá - Colombia.

Silva, Armando. (2005). Polvos de ciudad: Columna Imaginarios globales publicada por el periódico El Tiempo 2004. La multitud conectada. Editorial sociedad cultural la balsa. Colombia.

Silva, Armando. (1978). La Comunicación Visual. Como teoria y metodo para la lectura de las Artes y sistemas visuales. Bogotá - Colombia. Fondo Editorial Suramericana.

Silva, Armando. (2006a). Imaginarios urbanos. Bogotá: Editorial Tercer Mundo.

Silva, Armando. (2006b). Centros imaginados de América Latina. Lugares e imaginarios en la metrópolis. Barcelona: Anthropos.

Silva, Armando. (2013). Atmósferas ciudadanas: grafiti, arte público, nichos estéticos. Bogotá - Colombia. Universidad Externado de Colombia.

Silva, Armando. (2013). Imaginarios: el asombro social. Bogotá - Colombia. Universidad Externado de Colombia. 
Váquez, Fernando. (2004). La cultura como texto, lectura, semiótica y educación. Segunda edición. Bogotá. Editorial Pontificia Universidad Javeriana.

\section{Bibliografía indirecta}

Amendola, G. (1998). La ciudad postmoderna. España: Celeste ediciones.

Castoriadis, Cornelius. (1983). La institución imaginaria de la sociedad, vol. 1. Barcelona: Tusquets.

Castoriadis, Cornelius. (2005). Los dominios del hombre. Barcelona: Gedisa.

Delgado Ruíz, Manuel. (1999). Ciudad líquida, ciudad interrumpida. Editorial Universidad de Antioquia. Facultad de Ciencias Humanas y Económicas de la Universidad Nacional de Colombia. Medellín - Colombia.

Delgado Ruíz, Manuel. (2007). Sociedades Movedizas: pasos hacia una antropología de las calles. Editorial Anagrama, S.A. Barcelona - España.

Eco, Umberto. (1970). La definición del arte: lo que hoy llamamos arte ¿ha sido y será siempre arte? - Barcelona España. Diagràfic, S.A.

Eco, Umberto. (1995). Semiótica y filosofía del lenguaje. Barcelona: Lumen.

Eco, Umberto. (2007). Historia de la fealdad. Italia. G. Canales, Borgaro Torinese (TO).

Fiske, John. 1984. Introducción al estudio de la comunicación. Colombia. Editorial Norma.
Freud, Sigmund. (1900). La interpretación de los sueños (Trad. Luis López Ballesteros, Madrid, Biblioteca Nueva, T1, 1992).

Freud, Sigmund. (1915-1916). Conferencias de introducción al psicoanálisis. En Obras completas (T. XV y XVI). Buenos Aires: Amorrortu Editores.

Mukarovsky, Jan. (1997). Escritos de estética y semiótica del arte. Colección Comunicación Visual. Editorial Gustavo Gili, S.A. Barcelona España.

Sausurre, Ferdinand. (1916). Cours de linguistique génerale, Paris, Payot (trad. Esp., Buenos Aires, Losada).

Searle, John. (1995). La construcción de la realidad social. Ediciones Paidos Ibérica, S.A. Barcelona - España. 